\title{
A problemática da economia solidária: um novo modo de gestão pública?
}

\author{
Genauto Carvalho de França Filho*
}

\section{Resumo}

Este artigo discute a economia solidária numa perspectiva internacional, situando o contexto de surgimento desse fenômeno e o tipo de problemática que ele suscita. Apresenta uma abordagem original para sua interpretação, baseado em argumentos da sociologia e da antropologia econômica, indicando o que tal fenômeno tem como elementos para a reflexão e a prática de um modo renovado de gestão pública.

Palavras-chave.: Economia Solidária. Gestão Pública. Economia Plural. Economia Popular. Antropologia Econômica.

\begin{abstract}
This article discusses the subject of solidarity-based economy under an international perspective. The article develops the context in which the phenomenon emerges as well as the problems that arises. It is developed an original approach based on sociological and anthropological features. The article proposes another practices for a public management model.
\end{abstract}

Key Words: Solidarity-Based Economy. Public Management. Pluralistic Economy. Economical Anthropology. Popular Economy.

\section{Introdução}

A temática da economia solidária tem conquistado uma visibilidade cada vez maior nos últimos anos. No ambiente acadêmico, publicações a esse respeito já aparecem em diferentes campos disciplinares como economia, sociologia ou administração. Esse recente interesse da academia parece refletir a própria dinâmica verificada na sociedade, através da iniciativa de diferentes atores associativos, representantes dos poderes públicos e mesmo entidades sindicais, o que tem levado o tema a ocupar lugar de destaque em certos eventos, como foi o caso do Fórum Social Mundial, realizado em Porto Alegre.

Alternativa real à crescente crise do emprego, verificada em diferentes sociedades, ou mero paliativo à crise de ajustamento de um sistema capitalista que se renova, são diferentes os diagnósticos acerca do alcance e dos limites do tema. Tais diagnósticos apenas indicam as razões desse súbito interesse pelo tema, pois de algum modo este sugere uma mudança de referências para se pensar a realidade. É que a crescente relevância do tema acontece exatamente no atual contexto de reconfiguração das relações entre Estado e mercado, onde desponta com força a idéia de um terceiro setor.

Contudo, economia solidária e terceiro setor podem ser considerados como sinônimos? Parece que não. Embora uma correlação direta entre esses termos pareça evidente (pois em ambos os casos, trata-se de empreendimentos privados de interesse público), eles pertencem a universos semânticos distintos. Portanto, são diferentes os contextos sociopolíticos de emergência de cada termo, implicando interpretações distintas sobre o papel desempenhado por essas experiências, bem como, as respectivas posições que devem ocupar em relação ao Estado e ao mercado. Terceiro setor, por exemplo, é uma expressão tipicamente norte-americana, enquanto a noção de economia solidária, assim como a expressão "economia social", é uma formulação européia (FRANÇA FILHO, 2002b). A primeira está impregnada da idéia de filantropia, como é próprio da tradição anglo-saxônica, e se orienta mais para uma questão de ajustamento do sistema na sua capacidade de satisfazer necessidades sociais. A segunda é portadora de uma problemática histórica que está na própria origem da idéia de Estado social. Implica um debate sobre as possibilidades de cooperação econômica e as formas de 
manifestação da solidariedade na economia. É herdeira, portanto, de iniciativas históricas (cooperativistas, associativistas e mutualistas) capazes de sugerir formas de ação pública que foram mais tarde incorporadas pela instituição do Estado-Providência.

Já no nosso caso, a formulação mais próxima seria aquela de uma economia popular, uma construção tipicamente latino-americana. Diferenças substanciais pesam nesta definição em relação às demais, relacionadas fundamentalmente ao grau de institucionalização das experiências, que, no nosso caso, são menos expressivas nesse aspecto, considerando-se o próprio contexto de "incompletude" da nossa modernidade. Em todo caso, a tônica desse campo de experiências refere-se ao seu caráter heterogêneo, variando de iniciativas extremamente precárias até formas mais estruturadas de organização coletiva. Como síntese desses vários conceitos importa destacar aqui o caráter associativo ou cooperativo da maioria dessas experiências, que partindo da própria sociedade inventam formas inéditas de produção e distribuição de riqueza, isto é, de fazer economia.

Entretanto, este texto não pretende discutir cada um desses conceitos de forma pontual. Nosso propósito é sugerir um modo particular de apreensão da natureza intrínseca de uma economia solidária, admitindo que estamos diante de um fenômeno complexo, como é próprio da contemporaneidade. Segundo nossa hipótese, tal fenômeno representa formas inéditas de ação pública. Dito de outro modo, consideramos que existe um modo original de agir organizacional, elaborado através dessas iniciativas. Isso se deve à própria natureza do fenômeno, isto é, à sua capacidade de articular lógicas de ação bastante diferenciadas na sua dinâmica. Em se tratando de organizações que visam antes a realização de objetivos sociais, culturais ou políticos, a dimensão econômica do seu projeto coletivo tende a aparecer de modo subordinado às demais dimensões; de certo modo, como um meio para a realização destas. Através dessas experiências, surgem respostas concretas a certas demandas e necessidades sociais, que, partindo da própria sociedade, muitas vezes se articulam com outras instâncias (como os poderes públicos), dando origem a arranjos organizacionais bastante particulares. Esses arranjos "organizativos" - que alguns tenderiam a chamar de "interorganizações" - são tão heterogêneos nas suas múltiplas formas assumidas e, algumas vezes, tão precários do ponto de vista da sua capacidade institucional, que, para sua gestão, exigem um agenciamento de lógicas de ação extremamente complexo, haja vista as diferentes legitimidades que são mobilizadas na sua prática.

Dessa forma, ao se enfrentar certas demandas e necessidades sociais - que configuram, evidentemente, problemas públicos concretos -, não estaríamos, com essas experiências de economia solidária, diante de uma forma renovada de gestão pública? É exatamente a hipótese de elaboração de um inédito modo de gestão pública, através desse fenômeno, que iremos explorar neste trabalho. Para tanto, num primeiro momento, iremos apresentar essa temática da economia solidária no plano internacional, sublinhando em particular sua origem como conceito, seu contexto de emergência como fenômeno e o tipo de problemática que suscita. Essa abordagem do tema compreende, essencialmente, uma visão da realidade da Europa e da América Latina, em que se busca, nos dois contextos, descrever o fenômeno e algumas implicações práticas do tipo de problemática enfrentada. Depois, discutiremos um modo específico de interpretação desse fenômeno, a partir de uma perspectiva da antropologia econômica que consideramos fecunda para a apreensão da sua natureza específica. No final, desenvolveremos algumas considerações e levantaremos alguns questionamentos que procuram elucidar, considerando esse tipo de fenômeno, a elaboração de formas inéditas de gestão pública.

\section{Discutindo um conceito: a economia solidária como expressão de uma nova forma de solidariedade}

Em diferentes contextos societários, o termo economia solidária parece indicar que atualmente estão emergindo novas formas de solidariedade. Essas novas formas de solidariedade fazem alusão à iniciativa cidadã, ao mesmo tempo que se opõem às formas abstratas de solidariedade, praticadas historicamente pelo Estado, de um lado, e às formas tradicionais de solidariedade marcadas pelo caráter exclusivamente comunitário. A nossa hipótese é a de estamos diante de um fenômeno inédito, pois essas experiências não parecem se orientar apenas conforme o registro de uma socialidade típica da Gemeinschaft (comunidade), princípio comunitário (Tönnies), ou seja, uma socialidade comunitária (Weber), ou ainda uma solidariedade mecânica característica das sociedades tradicionais (Durkheim). De fato, se um tipo de dinâmica comunitária marca essas experiências, sua expressão não parece se identificar apenas com o registro de um comunitarismo herdado (conforme nos lembra Caillé e Laville), "na medida em que ela emana de um comunitarismo muito mais escolhido como referência 
coletiva a um bem comum do que imposto pelo costume". ${ }^{1}$ Além disso, o caráter inédito dessas novas formas de solidariedade também reside na afirmação de uma dinâmica comunitária numa sociedade em que as relações relevam primeiro de uma solidariedade orgânica (Durkheim) ou da Gesellschaft (sociedade), princípio societário (Tönnies), ou ainda da socialidade societária (Weber).

Portanto, experiências associativistas e cooperativistas, em geral, marcadas por uma dinâmica comunitária do ponto de vista interno, mas ao mesmo tempo abertas ao espaço público - isto é, voltadas para o enfrentamento de problemáticas públicas locais -, são alguns elementos que parecem constituir uma primeira característica central do fenômeno da economia solidária.

\section{0 contexto europeu de emergência de uma economia solidária}

Na Europa, e em particular na França, as preocupações relativas à economia solidária são compreendidas no contexto de crise da chamada sociedade salarial, manifestada pela escassez do trabalho na sua forma mais conhecida, isto é, o emprego em tempo pleno, por uma vida inteira, acompanhada do seu cortejo de exclusão. Portanto, trata-se de uma dupla crise, do emprego e da socialização (ou da integração), que aponta para o esgotamento da chamada "sinergia Estado-mercado" - característica do pós-guerra, período conhecido como "trinta glorioso" - e que se traduz na chamada "crise do Estado-Providência".

Essa crise revela os limites dessas duas esferas, mercado e Estado, como reguladoras da atividade econômica e social, e está acompanhada de novos questionamentos sobre a posição paradoxal do trabalho nas sociedade contemporânea. Como ressalta Martin (1994, p.246), "o trabalho não pode mais assegurar sua função reguladora, ao mesmo tempo em que permanece como principal vetor de integração". Paralelamente à crise de legitimidade do Estado-Providência é que surgem as chamadas novas formas de solidariedade, algumas delas mais conhecidas como "solidariedade de proximidade" - que se imaginava esgotada pela providência estatizante mecânica e atomizante - pela qual as pessoas tentam se reapropriar do seu futuro. Segundo Laville (1997, p.63), emerge

"uma forma de política da vida cotidiana (...) através do debate público de problemas sociais e econômicos que hoje não são inteiramente resolvidos nem pelo setor publico, nem pelo setor privado. Dezenas de milhares de experiências são testemunhadas: creches associativas e atividades em torno da escola, lugares de expressão e de atividades artísticas como os 'cafésmusicais', restaurantes multiculturais de bairro, régies de quartier, iniciativas de inserção (profissional, econômica,...), de ajuda a domicílio, de esporte ou de proteção do meio ambiente".

Outros enxergam nessas experiências, a possibilidade de realização de uma nova exigência: "estabelecer um novo compromisso entre economia monetária e não-monetária, sem romper com a idéia que o trabalho permanece o grande integrador" (MARTIN, 1994, p.246).

\section{A prática de uma economia solidária européia: dilemas e desafios}

Acabamos de mencionar alguns exemplos do fenômeno da economia solidária no contexto europeu. Porém, importa salientar a diversidade de suas formas assumidas, o que nos leva a sugerir um modo de agrupá-las (FRANÇA FILHO 2001, 2002a, 2002d, 2003a). Nesse sentido, conforme nossa abordagem, em relação ao contexto europeu, mais geral, e francês, em particular, existem quatro formas principais de economia solidária. São quatro experiências que denominamos como: o comércio justo, a finança solidária, a economia sem dinheiro e as empresas sociais. É uma tipologia que se apoia fundamentalmente no critério da natureza da atividade empreendida.

\footnotetext{
${ }^{1}$ Prefácio de França Filho e Dzimira (2000). É verdade que no contexto latino-americano, essa dinâmica comunitária ainda é fortemente influenciada pelos costumes, próprios das práticas de reciprocidade tecidas no cotidiano. Porém, a esse aspecto, deve-se acrescentar uma dimensão de escolha das pessoas, ao participarem dos projetos e decidirem democraticamente sobre o seu destino.
} 


\section{0 comércio justo}

Esse fenômeno resulta da ambição de se estabelecer uma solidariedade internacional, o que reflete preocupação com a possibilidade de se implantar uma regulação internacional fundada sobre novas relações econômicas e comerciais. O seu objetivo é estabelecer relações comerciais mais justas entre países do Norte (consumidores, em particular) e certos produtores de países do Sul. A essa finalidade é acrescentada outra, mais sob o registro de uma pedagogia política: constituir uma rede de consumidores, capaz de sensibilizar a opinião pública quanto às injustas regras do comércio internacional, empreendendo-se ações - sob a forma de campanhas, manifestações etc. - junto a grandes instâncias institucionais de decisão em matéria política e econômica.

As organizações do comércio justo estabelecem contratos com organizações de pequenos produtores (organizados em cooperativas) para a compra e venda de produtos (em geral, produtos agrícolas ou artesanais). A idéia é encontrar canais de distribuição para escoar essa produção, por um preço considerado justo para o pequeno produtor. Assim, o objetivo é eliminar, ao máximo, o número de intermediários entre produtor e consumidor.

Herdeiro do antigo comércio alternativo - que funcionava como uma espécie de rede paralela de solidariedade para a distribuição de produtos terceiro-mundistas na Europa -, o comércio justo evoluiu através de um processo de patentiamento de certos produtos, ${ }^{2}$ entre os quais, o exemplo mais conhecido hoje talvez seja o do café Max Havelaar.

Hoje, o desenvolvimento desse campo do comércio justo implica a necessidade de se distinguir as experiências cujo universo de distribuição está limitado às redes das assim chamadas "boutiques associativas" ou "armazéns do mundo" - lojas (associativas) de venda desses produtos, caso da rede Artisans du Monde, na França daquelas iniciativas voltadas para os grandes canais de distribuição, ou seja, as grandes cadeias de supermercados.

O processo de patentiamento de produtos, e sua conseqüente entrada no âmbito da distribuição de massa, muito contribuiu para o aumento das vendas dos chamados produtos équitables ou "justos", trazendo para esse universo de experiências, certas lógicas funcionais que passam também a interagir na dinâmica dessas formas de organização.

Dessa forma, observa-se que entre a dimensão socioeconômica e a dimensão política, a prioridade do comércio justo implica tanto atividades de trocas comerciais - mais ou menos receptivas à grande distribuição, e mais ou menos importantes segundo o volume das transações -, quanto uma pedagogia política. Portanto, esse campo de experiências aparece marcado por uma tensão entre lógicas distintas. Esse conflito se traduz pela oposição entre certos imperativos funcionais - impostos pela necessidade de aumento das vendas dos produtos, e conseqüentemente da sua abertura para a grande distribuição - e a necessidade de afirmação do sentido do projeto, pela sua contribuição para mudar as injustas condições do comércio mundial, numa perspectiva de conscientização do consumo.

\section{A finança solidária}

Nesse universo, consideramos um conjunto de experiências - também conhecidas como microcrédito, poupança solidária, microfinança, finança de proximidade etc.) - que participam da construção de outro tipo de relação com o dinheiro. $\mathrm{O}$ objetivo da finança solidária, dito de modo simplificado, é permitir às pessoas excluídas do sistema bancário, criarem seu próprio emprego. Portanto, o desafio desse campo de experiências gira em torno da necessidade de democratização do acesso ao crédito, que vem fazer face ao problema da seletividade nesse acesso e sua conseqüente limitação de oferta, ligada à busca de rentabilidade das instituições financeiras.

\footnotetext{
${ }^{2} \mathrm{Na}$ origem do comércio justo (aproximadamente, no início da década de 1970), há uma convergência entre ONGs de países do Sul (envolvidas em iniciativas de organização popular) e associações ecológicas ou de defesa dos direitos humanos de países do Norte - tudo isso num contexto de queda dos preços das matérias-primas no comércio internacional.
} 
Entretanto, mais do que uma questão de democratização do acesso ao crédito, o que também (e sobretudo) orienta essas iniciativas é uma preocupação com a chamada utilidade social do investimento financeiro. Essas experiências têm como objetivo uma aplicação ética do dinheiro, articulando, por exemplo, esforços na luta contra a exclusão, pela preservação ambiental, em trabalhos de ação cultural, de desenvolvimento local etc.

Existem vários exemplos de iniciativas de finança solidária. Na França, citamos o caso dos Cigales (Clubs d'Investisseurs pour une Gestion Alternative et Locale de l'Épargne, traduzido como "clubes de investidores para uma gestão alternativa e local da poupança"), que se articulam em rede. Essas associações mobilizam uma poupança de proximidade (a partir de seus membros associados) que é investida em projetos locais, visando reforçar o tecido econômico local e os laços sociais. O propósito é fomentar o desenvolvimento e a criação de pequenas empresas regionais. De modo geral, o investimento dá prioridade ao aspecto local e ao caráter de utilidade social da empresa, mas cada clube possui autonomia decisória. Os Cigales funcionam como uma espécie de sociedade de capital de risco solidário de proximidade. Além desse gênero de iniciativa (em que é possível considerar inúmeros outros exemplos), esse campo da finança solidária também compreende várias outras práticas, como é o caso dos fundos de aplicação éticos ou solidários, já oferecidos por certos bancos tradicionais. Nesse caso, o poupador renuncia a uma parte da remuneração da sua poupança ou aplicação, em nome da utilidade social do investimento feito.

Ainda que a grande maioria dos empreendimentos no campo da finança solidária seja de pequeno porte, hoje, cada vez mais, surgem grandes instituições de crédito solidário. Na França, é o caso, por exemplo, da NEF (Nouvelle Economie Fraternelle), constituída como banco em 1999, e, desde 1996, da Caisse Solidaire de Roubaix, a primeira iniciativa nesse país de uma sociedade financeira com vocação inteiramente solidária. No entanto, a França não possui uma tradição de grandes bancos solidários como a Alemanha, Suíça, Bélgica, Inglaterra ou Holanda. Neste último caso, o exemplo da Triodos parece significativo: atuando em campos muito diversos, a Triodos tornou-se o principal investidor em parques eólicos no seu país. Esse banco solidário ainda financia um quarto da alimentação biológica da Holanda.

Pela diversidade de experiências, esse campo se apresenta bastante heterogêneo quanto ao conteúdo das iniciativas, implicando o que consideramos aqui como um risco liberal. Ou seja, algumas experiências de finança solidária apresentam certa vulnerabilidade, no sentido da possibilidade de sua apropriação por um discurso liberalizante do ponto de vista econômico. A concentração da ajuda sobre empreendedores individuais, como acontece em algumas experiências, ${ }^{3}$ pode conduzir a uma situação em que antigos assalariados se transformam em novos terceiros subcontratantes. Trata-se de uma evolução instrumental, afetando a dinâmica das relações trabalhistas, acentuada pela moda do microcrédito junto às grandes instituições financeiras internacionais que defendem a multiplicação de microempresas independentes como alternativa positiva às regras protetoras da relação assalariada. A finança solidária difere da abordagem liberal por dois aspectos: naquela experiência, a seleção dos projetos nos quais investir segue critérios de utilidade social, e é enfatizada a importância do acompanhamento do projeto, uma vez iniciado.

Assim, observamos que - à imagem da própria dinâmica mais geral da economia solidária, tal como definido anteriormente - o universo da finança solidária se posiciona numa imbricação de três economias. Nesse campo tão diverso e complexo, certas experiências parecem mais próximas do setor bancário (mercantil), mantendo com ele relações de parceria privilegiadas, para encontrar o essencial dos seus recursos. Outras experiências se assemelham mais a uma iniciativa "parapública", tal a intensidade da relação com o pólo não-mercantil, em que os subsídios públicos são vitais para a sobrevivência da associação. Outras experiências parecem ainda situadas numa posição mais equilibrada entre os três pólos (posição sempre difícil de manter), nutrindo o essencial dos seus recursos numa dinâmica recíproca.

${ }^{3}$ É o caso na França da Adie ("Associação pelo Direito à Iniciativa Econômica"), que financia microprojetos individuais de criação de empresas, por desempregados. A Adie se inspira no exemplo, hoje considerado emblemático, do Grameen Bank, em Bangladesh - considerado o primeiro banco para pobres do mundo - que apoia iniciativas de camponeses sem-terra. Tentando responder a essa crítica, que situa a experiência da Adie mais pelo registro de uma economia da inserção (de caráter assistencialista) do que propriamente uma economia solidária, M. Novak (fundadora dessa experiência) considera que se trata de buscar uma terceira via entre o emprego clássico e a assistência: a via do trabalho independente. 
Desse modo, a eficácia e a vitalidade dessas experiências se desenrolam numa relação de interdependência freqüentemente conflitante, devido ao difícil exercício de uma parceria que envolve diferentes lógicas de ação e mobiliza diversas formas de legitimidade. Para a maioria das experiências de finança solidária, o desafio se coloca em termos de sua autonomia e preservação do projeto inicial, em face das injunções do mercado e dos poderes públicos. Logo, essas iniciativas parecem, em grande parte dos casos, conscientes de certas derivas históricas dos setores mutualistas e cooperativistas (símbolos da economia social na França). Estes, tornaramse, na prática - isto é, do ponto de vista da sua dinâmica de funcionamento -, imagem e cópia fiel de uma empresa convencional como tipo organizacional, pois é valorizada uma estrutura altamente tecnoburocrática de gestão.

\section{A economia sem dinheiro}

São iniciativas cujo objetivo é a criação de formas de trocas ou intercâmbios econômicos alternativos àquelas praticadas segundo uma lógica de mercado. Tais iniciativas se situam numa escala local e buscam a articulação em redes, como modo de organização territorial, visando enfrentar a exclusão social.

Três tipos principais de experiências caracterizam esse campo: primeiro, a autoprodução coletiva. Segundo, os sistemas de trocas locais - conhecidos na França como systèmes d'échanges locaux (SEL); tauschring,, na Alemanha; redes de economia local (REL), na Itália; porém, mais conhecidos através das experiências anglosaxônicas denominadas local exchange trading system (LETS) -e, terceiro, as redes de trocas recíprocas de saberes, conhecidas na França como réseaux d'échanges reciproques de savoirs (RERS). Nesses dois últimos casos, os vários termos podem ser resumidos ao que se convencionou chamar na América Latina de "clubes de troca".

Um SEL ou LETS é uma associação de pessoas - em certos casos, centenas, ou até milhares de associados para trocar de outro modo (em relação à forma mercantil) bens e serviços. O conjunto dos intercâmbios/trocas é contabilizado pela associação com o auxílio de uma moeda fictícia, e as dívidas são reguladas (mas jamais eliminadas) através de um sistema de compensação. A natureza das atividades ou bens trocados é bastante diversa: guarda de crianças, aulas (de línguas, culinária etc.), serviços de reparo em geral (marcenaria, encanamento, eletrônica etc.), produtos artesanais, objetos usados, serviços de jardinagem ou domésticos, empréstimo de ferramentas, entre outros.

A origem dessas experiências remonta a 1976, na cidade de Vancouver, no Canadá. Rapidamente, tais iniciativas se espalharam, principalmente, em países como EUA, Inglaterra e Austrália. Essa origem está relacionada a contextos de crise econômica aguda (fechamento de fábricas etc.), acompanhada do aparecimento de múltiplas experiências cooperativistas e comunitárias. Na França, o primeiro SEL foi criado em Lyon, em 1994. A estimativa é de que hoje existam mais de mil experiências do gênero em todo o mundo.

Os SEL ou LETS não provêm de uma forma de troca mercantil, pois trata-se de um somatório de trocas (relações) bilaterais contabilizadas numa perspectiva de compensação multilateral, e não-instantânea, das dívidas que devem perdurar. Vale ressaltar que o sentido do sistema é o de fomentar uma dinâmica de dívidas e créditos a favor de uma perpetuação das relações sociais (MAUSS, 1950; FRANÇA e DZIMIRA, 1999 e 2000). A mesma reciprocidade também pode ser encontrada nas experiências das redes de trocas recíprocas de saberes (RERS - réseaux d'échanges reciproques de savoirs). Todavia, de modo diferente do verificado nos LETS, nessas iniciativas, a regulação das dívidas (também nunca eliminadas) ocorre pela própria bilateralidade da troca (sempre não-instantânea), e não mais pela multilateralidade das trocas relacionadas à totalidade associativa. Por outro lado, nessas experiências não se adota moeda local. São efetuadas trocas diretas de um saber por outro. Com o intuito de igualmente alimentar as relações sociais (o laço social), essas iniciativas surgiram na França em meados da década de 1970, espalhando-se em seguida para outros pontos da Europa, até atingir, nos dias de hoje, mais de 40.000 pessoas.

Na visão de uma das fundadoras do RERS (C. Héber-Suffrin), tais experiências têm um objetivo maior que é o de construir uma cultura da reciprocidade, definida como "uma tentativa de reequilíbrio permanente", numa perspectiva de encontro coerente entre alteridade e igualdade em que "ela é uma tensão permanente, construtiva e cognitiva" (C. HÉBER-SUFFRIN, 1998 apud LAVILLE, 1999). A singularidade dessas experiências em 
relação a certas atividades ilegais - ou à simples "viração" em família ou entre amigos - está na sua inserção no espaço público, revelando uma forma de solidariedade voluntária e um modo de relação igualitário entre os membros da associação.

Esse campo da economia solidária apresenta uma característica fundamental em relação aos demais, que se refere ao papel decisivo do pólo não-monetário. Em grande parte dos casos, a expressão mais destacada de uma lógica de reciprocidade não parece significar sua assimilação a uma espécie de revivescência de formas antigas de solidariedade comunitária. Isso ocorre pelo seu caráter democrático e por sua inserção no espaço público.

Em função do deslocamento do pólo econômico dominante (do não-mercantil para o não-monetário), esse campo está sujeito a certos conflitos cuja natureza muda em relação à clássica confrontação Estado versus mundo associativo, particularmente marcante na França.

\section{As empresas sociais}

Considerar a idéia de empresa social como categoria tipológica pode parecer redundante. Pois, também são empresas sociais, poderíamos assim chamar, que participam da finança solidária ou do comércio justo. Entretanto, pretendemos com esse termo, fazer referência a um certo número de experiências de empreendedorismo social voltadas para atividades muito variadas.

Mas, o que chamamos de empresa social? Uma primeira compreensão do termo sugere a idéia de organizações privadas desenvolvendo atividades comerciais, mas com finalidade social. Essa primeira aproximação do objeto nos parece um tanto quanto superficial, não permitindo visualizar a complexa natureza do fenômeno. De acordo com Clément e Gardin (1999), duas definições sobressaem no inventário da literatura sobre o tema, apontando para duas abordagens distintas: a primeira é fruto das pesquisas realizadas pela Organização para Cooperação e Desenvolvimento Econômico (OCDE) e a segunda tem origem nos trabalhos da rede Emes (Emergence of European Social Enterprises). ${ }^{4}$

A primeira definição estabelece que "a empresa social faz referência a toda atividade privada de interesse geral, organizada a partir de uma démarche empresarial, não tendo como razão principal a maximização do lucro, mas a satisfação de certos objetivos econômicos e sociais, assim como à capacidade de dispor, pela produção de bens e serviços, de soluções inovadoras aos problemas de exclusão e de desemprego". ${ }^{5}$

A segunda definição (da qual nos sentimos mais próximos) destaca o caráter original desse tipo de organização, considerado como estando numa encruzilhada de lógicas diversas (LAVILLE e NYSSENS, 1999). De um lado, ainda que o poder não se baseie na controle do capital - em contraste com a lógica de uma empresa convencional -, ela desenvolve trocas comerciais. Por outro lado, seu grau de autonomia permite distingui-la de uma empresa pública, ainda que na maioria dos casos seja beneficiada por subsídios do poder público. Considerando a organização socioeconômica dessas empresas, a partir da idéia de interação entre diferentes registros do comportamento econômico - ou três pólos: mercantil, não-mercantil e não-monetário -, esses trabalhos procuram afinar sua caracterização. Nesse sentido, dois aspectos se destacam:

- participar da estrutura de poder (assalariados, usuários, voluntários) e seus papéis apresentam um caráter difuso, aproximando-se, assim, do conceito de multiples stakeholders enterprises (BORZAGA e MITTONE, 1997; PESTOFF, 1998);

\footnotetext{
${ }^{4}$ Essa rede reúne pesquisadores de 15 países europeus, para definir as características sociais, econômicas e políticas dessas organizações.

${ }^{5}$ A partir dessa definição (bastante formalista) e de certas características funcionais decorrentes, a OCDE oferece uma ampla variedade de exemplos do que seja empresa social: empresas de inserção francesas, empresas inclusoras belgas ou finlandesas, cooperativas sociais italianas, cooperativas de trabalho associado espanholas, empresas de comunidades locais alemãs (ex-empresas alternativas), empresas comunitárias irlandesas ou escocesas (community business), empresas intermediárias britânicas (intermediate labour markets organizations), empresas de inserção portuguesas, cooperativas de serviços sociais suecas, empresas comunitárias austríacas, empresas comerciais com finalidade social americanas (community based business, community wealth enterprises), movimento comunitário quebequense, grupos comunitários neozelandeses, cooperativas mexicanas.
}

${ }^{6}$ É importante assinalar o termo stakeholders, em alusão às pessoas com interesses comuns, no lugar de stockholders, ou seja, pessoas acionárias. O conceito de stakeholders é particularmente importante, pois enfatiza a dimensão democrática do funcionamento da empresa, e a idéia de empregar o lucro obtido para se atingir objetivos sociais e não a remuneraração do capital. 
- no que se refere aos objetivos organizacionais, a finalidade de uma empresa social é colocada em termos de serviços à coletividade, "seja através de externalidades positivas que ela produz e/ou de igual acesso de todos ao serviço, que ela desenvolve" (CLÉMENT e GARDIN, 1999). Isso traduz o caráter de utilidade coletiva ou de utilidade social, próprio desse tipo de iniciativa, o que, inclusive, justifica a natureza de sua propriedade (ou de seu poder), que é estar aberta à participação dos atores organizacionais a múltiplos estatutos.

Em geral, as empresas sociais despertam um interesse particular por parte do poder público na Europa. Este tende a ver essas experiências como formas privilegiadas de potencialização de certas políticas sociais, estabelecendo parcerias importantes com muitas dessas empresas. O grande desafio dessas iniciativas é preservar seu funcionamento democrático (intimamente ligado ao grau de autonomia da experiência) em face dos riscos de instrumentalização institucional. Isso significa que diante das injunções do Estado e do mercado, o desenvolvimento das empresas sociais as coloca permanentemente diante do risco de isomorfismo institucional. Isto é, o risco de funcionar como empresa privada ou serviço público. Dito de outro modo, uma tendência à profissionalização da gestão das associações (em termos tecnoburocráticos) acompanha um certo nível de crescimento, implicando submeter a dimensão associativa (autônoma e espontânea) aos imperativos funcionais (lógica instrumental) fundados num modo formal de gestão e na busca de resultados passíveis de quantificação.

O isomorfismo institucional é apenas uma conseqüência, entre outras possíveis, da tensão dialética característica dessas formas de organização, atravessadas por lógicas diversas. Na maioria das vezes, elas são uma iniciativa cidadã (baseada em ideais de autonomia) e, simultaneamente, modeladas no quadro de certas políticas públicas (experiências instrumentalizadas). A tensão será mais ou menos forte conforme o tipo de organização e o seu contexto de inserção, ou seja, as características do contexto político no qual a empresa estiver inserida.

\section{A realidade brasileira: um projeto de economia popular e solidária}

Feita essa caracterização do contexto europeu, importa indagar sobre a especificidade de uma economia solidária brasileira. Se na realidade européia a economia solidária se exprime através de variadas formas - seja entre as empresas sociais, o comércio justo e em relação às diferentes práticas de finança solidária e de uma economia sem dinheiro -, no Brasil, a economia solidária também é marcada pela diversidade.

\section{Uma diversidade de experiências}

Nesse momento, o universo da economia solidária no Brasil está em pleno processo de estruturação, haja vista a criação recente da Secretaria Nacional de Economia Solidária (Senaes), ligada ao Ministério do Trabalho, assim como a organização dos fóruns estaduais de economia solidária e das redes de iniciativas, em que se destaca a rede brasileira de socioeconomia solidária, criada na ocasião do I Fórum Social Mundial, realizado em Porto Alegre em 2001, e que integra diversas entidades de fomento à economia solidária em todo país. Como nos esclarece Singer (2002, p. 124), essa "é uma rede eletrônica que enseja o intercâmbio de notícias e opiniões, e está se transformando também em rede eletrônica de intercâmbio comercial entre cooperativas e associações produtivas e de consumidores". Nesse sentido, importa ressaltar que, além das próprias ações diretamente empreendidas pelos grupos, o universo da economia solidária conta com uma série de entidades que atuam como organizações de apoio e fomento.

Nesse universo, encontramos um número crescente de iniciativas de finança solidária denominadas genericamente de "bancos populares". Na maior parte dos casos, são cooperativas de crédito que ampliam a prática do microcrédito para as pequenas iniciativas de organizações coletivas populares. Geralmente, essas iniciativas de finança solidária contam com apoio do poder público ou da própria sociedade civil, através da ação de algumas ONGs. ${ }^{7}$ ${ }^{7}$ Além dos bancos populares, esse campo conhece alguns casos bastante inovadores, como a experiência da associação Bansol, criada por estudantes e al-
guns professores da Faculdade de Administração da Universidade Federal da Bahia (UFBA). Além do apoio sob a forma de microcrédito, o Bansol (que se 
Outro exemplo expressivo são os sistemas de trocas locais, mais conhecidos como "clubes de trocas". São "formados por pequenos produtores de mercadorias, que constroem para si um mercado protegido, ao emitir uma moeda própria que viabiliza o intercâmbio entre os participantes" (SINGER, 2000; p.23). Porém, nem todos os clubes de troca adotam moeda fictícia. Em todo caso, seja de uma forma ou de outra, tais práticas alimentam a proliferação de um circuito de trocas não-monetárias, cujo fundamento é uma lógica de dádiva, ou seja, o objetivo das trocas é, para além da satisfação utilitária dos bens ou serviços, fortalecer ou criar vínculos sociais entre as pessoas envolvidas. Por esse aspecto, tal tipo de prática constitui uma dimensão intrínseca às próprias formas de vida dos setores populares, fazendo parte da sua tradição. A novidade é que tais práticas se inscrevem no quadro da ação associativa, isto é, adquirem um certo grau de institucionalização. Nesse sentido, a aparição do fenômeno, como na França, está relacionada não apenas ao aumento do desemprego, como na maior parte dos casos, mas também a razões pessoais de busca de outras formas de troca econômica, para além do modo mercantil. Isso porque essas experiências não se restringem aos meios populares. Em alguns casos são uma iniciativa de redes sociais oriundas das classes médias urbanas. De todo modo, o aumento do fenômeno no Brasil não pode ser comparado à amplitude que atinge na Argentina. Diante da situação de crise econômica aguda, o país vizinho registrou uma multiplicação impressionante dessas iniciativas, cuja estimativa atual aponta para um número aproximado de cinco milhões de pessoas envolvidas.

Entretanto, é, sem dúvida, com uma nova dinâmica de experiências cooperativistas, ${ }^{8}$ batizadas de "cooperativismo popular", que se encontra a maior parte dos casos de economia solidária no Brasil. Estes, conhecem um crescimento importante a partir do início da década de 1990. Seja como cooperativas de produção ou de prestação de serviços, seja como cooperativas de consumo, ${ }^{9}$ seu campo de atividade varia, assim como seu grau de estruturação. Conforme nos explica Singer (2002, p.23), algumas cooperativas de produção industrial e de serviços são dotadas de muito capital, empregando melhor tecnologia e se mostrando competitivas nos mercados mundial ou nacional; enquanto outras, dotadas de capital modesto - produzindo pães, tecidos, vassouras, materiais reciclados etc., e cujas instalações produtivas foram apropriadas por antigos funcionários das firmas através de causas trabalhistas -, "empregam tecnologias herdadas de empresas antecessoras, enfrentando grandes dificuldades para se manter em alguns mercados". Quanto a este último aspecto, cabe ressaltar um certo número de cooperativas participando de um movimento de retomada, pelos trabalhadores, de empresas em estado de falência - particularmente evidente em função da importante crise industrial do início da década de 1990. Essas novas cooperativas pretendem se distinguir do cooperativismo tradicional, através da afirmação de uma dupla característica: a preocupação em adotar uma perspectiva de desenvolvimento local e solidário e se organizar em rede. O caso da Anteag (Associação Nacional dos Trabalhadores das Empresas Autogeridas) e o da Federação de Cooperativas de Trabalho do Estado de São Paulo aparecem como sinais importantes do nível de organização de algumas dessas iniciativas, nesse momento.

Assim, é possível observar que nesses casos de empresas solidárias se destacam as cooperativas de produção industrial, que, mesmo enfrentando dificuldades em assegurar o seu desenvolvimento, conseguem atingir um certo nível de estruturação e de organização do trabalho. Porém, isso não é o caso da maioria das experiências de cooperativismo popular, marcadas por um nível de instabilidade bastante expressivo. Em geral, essa instabilidade aparece ligada às precárias condições de desenvolvimento dessas iniciativas - sobretudo, no plano dos recursos materiais mobilizados, mas também no nível de renda auferido -, refletindo as próprias condições

define como uma associação de fomento à economia solidária) auxilia o desenvolvimento de empreendimentos solidários através da relação entre estudantes e atores das iniciativas. Concebida como um processo educativo, baseada no príncipio da reciprocidade, a intervenção visa a construção democrática de uma metodologia de gestão social e solidária., ou seja, adequada às características dessas formas de organização.

${ }^{8}$ De fato, como nos ensina Singer (2002, p.122), "o cooperativismo chegou ao Brasil no começo do século XX, trazido pelos emigrantes europeus. To mou principalmente a forma de cooperativas de consumo nas cidades e de cooperativas agrícolas no campo. As cooperativas de consumo eram em geral por empresa e serviam para proteger os trabalhadores dos rigores da carestia. Nas décadas mais recentes, as grandes redes de hipermercados conquistaram os mercados e provocaram o fechamento da maioria das cooperativas de consumo. As cooperativas agrícolas se expandiram e algumas se transformaram em grandes empreendimentos agroindustriais e comerciais. Mas nenhuma dessas cooperativas era ou é autogestionária. Sua direção e as pessoas que as operam são assalariadas, tanto nas cooperativas de consumo como naquelas de compra e venda agrícolas. Por isso, não se pode considerá-las parte da economia solidária".

${ }^{9}$ Dentre as cooperativas de consumidores se destacam aquelas de crédito, de habitação, de saúde e escolares. De acordo com Singer (2002, p.23), “essas cooperativas de consumidores somente pertencem a economia solidária, à medida que abrem suas portas para os profissionais que as operam". 
de vida dos grupos sociais, e implicando, na maioria das vezes, uma prioridade para a sobrevivência da empresa. Particularmente, esse é o caso de muitas cooperativas de trabalho que não dispõem de outro capital senão a própria força de trabalho dos seus membros associados. "Essas cooperativas procuram vender serviços (de limpeza, de manutenção, de reparação, de jardinagem, de vigilância etc.) a serem prestados nos locais, recorredo a meios fornecidos pelos compradores" (SINGER, 2000; p.23). Em todo caso, tais iniciativas devem ser distinguidas das empreiteiras de mão-de-obra, ou falsas cooperativas, oriundas de iniciativas empresariais de caráter predatório. Tais cooperativas - também conhecidas como "copergatas" - são montadas por firmas capitalistas visando explorar (e tornar mais precário) o trabalho dos cooperados, através da redução de custos obtida com o não pagamento das contribuições e dos encargos trabalhistas legais.

Além desses exemplos majoritários de cooperativismo popular, outras experiências menos difundidas no plano quantitativo merecem ser destacadas, em razão da originalidade de suas práticas. Em particular, é o caso de certas associações que desenvolvem simultaneamente a produção, a prestação de serviços, o sistema de trocas, a finança solidária etc. De modo geral, são experiências fortemente vinculadas a um quadro territorial específico de "pertencimento" (a um bairro, a uma região etc.), e que tentam através da sua prática enfrentar problemáticas locais. A título de ilustração, destacamos dois exemplos relevantes, originários da região Nordeste. O primeiro diz respeito à Associação dos Pequenos Agricultores do Município de Valente (Apaeb), no interior do estado da Bahia. Essa associação desenvolve diversas atividades de industrialização e comercialização de produtos agrícolas, além de aconselhamento técnico e capacitação de produtores, manejo de tecnologias socialmente apropriadas, concessão de crédito adequado às condições das famílias camponesas da região, uma escola-família agrícola etc. Num contexto local marcado pelo clima árido e as secas freqüentes, de um lado, e uma cultura política clientelista, do outro, a associação busca promover uma alternativa de desenvolvimento local visando, sobretudo, a garantia de vida digna das famílias em seu território (APAEB, 2002).

O segundo exemplo é o da Associação de Moradores do Conjunto Palmeira (Asmoconp), localizada na periferia de Fortaleza e mais conhecida como Banco Palmas. Após desempenhar um papel decisivo no processo de urbanização do bairro - até então uma favela -, a associação cria, em 1998, um banco popular (chamado Palmas) que financia uma série de atividades solidárias, abarcando praticamente o conjunto da cadeia socioprodutiva local. As ações envolvem várias linhas de microcrédito destinadas ao apoio de grupos produtivos que trabalham com artesanato (Palmart), confecções (Palmafashion) e material de limpeza (Palmalimpe). Abrangem ainda ações de incentivo ao consumo solidário local - através de cartão de crédito (Palmacard) -, de criação de um clube de trocas - inclusive, com adoção de uma moeda social no bairro (o Palma\$) - e de coordenação de um sistema de compras coletivas e de venda dos produtos do bairro através da criação de uma loja solidária. Entre as ações desenvolvidas pela Asmoconp também estão incluídas a criação de um laboratório de agricultura urbana (LAU), um projeto de criação de galinha caipira, uma escola de formação, um centro de estudos em socioeconomia solidária, entre outras. Pela originalidade de sua atuação, essa experiência pode ser considerada como uma das mais emblemáticas no campo da economia solidária no Brasil (JOAQUIM, 2002; MELO NETO e MAGALHÃES, 2003; FRANÇA FILHO e SILVA JUNIOR, 2003).

Além dos exemplos da Apaeb e da Asmoconp, é preciso reconhecer também a recente proliferação de uma série de experiências nos campos da reciclagem do lixo, da produção artística, da educação etc., em diversos planos, indo desde o caso de algumas creches populares até as iniciativas dos chamados cursinhos prévestibulares para estudantes carentes, entre inúmeros outros.

Convém também assinalar a ação de uma série de organizações de apoio e fomento às iniciativas de economia solidária. Entre estas, destaca-se o papel desempenhado pela Cáritas, uma entidade ligada à Conferência Nacional dos Bispos do Brasil (CNBB), que desde os anos 1980 já financiava milhares de pequenos projetos denominados PACS, (Projetos Alternativos Comunitários). Conforme nos explica Singer (2002, p.122), “uma boa parte dos PACS se destinava a gerar trabalho e renda, de forma associada, para moradores das periferias pobres das nossas metrópoles e da zona rural das diferentes regiões do país. Uma boa parte dos PACS acabou se transformando em unidades de economia solidária, algumas ainda dependentes da ajuda caritativa das comunidades de fiéis, outras conseguindo se consolidar economicamente mediante a venda de sua produção no 
mercado. Há PACS em assentamentos de reforma agrária liderados pelo Movimento dos Trabalhadores Rurais Sem-Terra (MST), confluindo com o cooperativismo agrícola criado pelos trabalhadores sem-terra".

O próprio MST vem se constituindo em outro ator relevante nesse âmbito, ao promover o assentamento de milhares de famílias em terras desapropriadas de latifúndios improdutivos. "O movimento decidiu que promoveria a agricultura sob a forma de cooperativas autogestionárias, dando lugar a outra modalidade de economia solidária no Brasil. Para realizar isso, 'criou em 1989 e 1990 o Sistema Cooperativista dos Assentados (SCA). Passados 10 anos de sua organização, o SCA conta com 86 cooperativas distribuídas em diversos estados brasileiros, divididas em três formas principais em primeiro nível: cooperativas de produção agropecuária, cooperativas de prestação de serviços e cooperativas de crédito"' (SINGER apud FERREIRA, 2002, p.123).

Da mesma forma, as chamadas Incubadoras Tecnológicas de Cooperativas Populares (ITCPs) - entidades universitárias destinadas à incubação de cooperativas e grupos de produção associada - constituem mais um importante componente da economia solidária no Brasil.

\begin{abstract}
"As ITCPs são multidisciplinares, integradas por professores, alunos de graduação e pósgraduação e funcionários, pertencentes às mais diferentes áreas do saber. Elas atendem grupos comunitários que desejam trabalhar e produzir em conjunto, dando-lhes formação em cooperativismo e economia solidária e apoio técnico, logístico e jurídico para que possam viabilizar seus empreendimentos autogestionários. Desde 1999, as ITCPs constituem uma rede, que se reúne periodicamente para trocar experiências, aprimorar a metodologia de incubação e se posicionar dentro do movimento nacional de economia solidária. No mesmo ano, a rede se filiou à Fundação Unitrabalho, que reúne mais de 80 universidades e presta serviços, nas mais diferentes áreas, ao movimento operário. A Unitrabalho desenvolve desde 1997 um programa de estudos e pesquisas sobre economia solidária. Um crescente número de núcleos da Unitrabalho em universidades acompanha e assiste às cooperativas, numa atividade que, em muitos aspectos, se assemelha aos das ITCPs" (SINGER, 2002; p.123).
\end{abstract}

Cabe ainda destacar o papel da Central Única dos Trabalhad ores (CUT) - a maior central sindical brasileira -, particularmente, através da sua Agência de Desenvolvimento Solidário (ADS), criada em 1999 em parceria com a Unitrabalho e o Departamento Intersindical de Estatísticas e Estudos Socioeconômicos (Dieese).

"A ADS vem difundindo conhecimentos sobre a economia solidária entre lideranças sindicais e militantes de entidades de fomento da economia solidária, por meio de cursos de pósgraduação em várias universidades, em parceria com a Unitrabalho. Uma de suas atividades prioritárias é a criação de cooperativas de crédito com o objetivo de estabelecer uma rede nacional de crédito solidário, em parceria com o Rabobank, importante banco cooperativo holandês" (SINGER, 2002; p.124).

Nesse âmbito das entidades de fomento, importa ainda registrar a ação de um número muito expressivo de ONGs agindo mais no plano local, e que são menos conhecidas nacionalmente. Muitas dessas formas de organização têm empreendido, mais recentemente, relações de parceria com os poderes públicos, sobretudo no plano das prefeituras. Evidentemente, que a composição e a característica do poder público local favorecerá mais ou menos essa interação. Em alguns casos, mais freqüentes entre prefeituras petistas, tem surgido um reconhecimento acerca das possibilidades de tais iniciativas como base para um processo de desenvolvimento local sustentável.

\title{
Economia popular e economia solidária
}

Apesar de sua diversidade, a economia solidária brasileira apenas pode ser compreendida mais adequadamente se inserida no contexto de uma economia popular. O termo faz alusão a um amplo circuito de relações produtivas, onde as atividades econômicas são parte da próprio tecido da vida social cotidiana. Trata-se de uma realidade heterogênea, um processo social que pode ser traduzido pela "aparição e expansão de numerosas pequenas atividades produtivas e comerciais, no interior de setores pobres e marginais das grandes cidades da 
América Latina", conforme sugere Razeto (1991). Os biscates ou ocupações autônomas, as microempresas familiares, as empresas associativas, ou ainda as organizações econômicas populares (OEP) são alguns exemplos de iniciativas desse universo.

Uma característica central desse fenômeno é a fundamental importância da solidariedade, base sobre a qual as atividades econômicas estão assentadas. Estas acabam funcionando como extensão ou prolongamento das próprias "solidariedades ordinárias", isto é, aquelas praticadas no cotidiano dos grupos primários. Por conseguinte, a economia popular encontra no tecido social local ou comunitário, e nas práticas de reciprocidade, os meios necessários para a própria criação de atividades.

Em resumo, o conceito de economia popular, ${ }^{10}$ envolve a produção e o desenvolvimento de atividades econômicas em bases comunitárias, o que implica uma articulação específica entre necessidades (demandas) e saberes (competências) no plano local. Contudo, em alguns casos, pode até se articular com o plano institucional, ou seja, quando o poder público reconhece o saber popular e tenta apoiá-lo por meio de assessoria técnica, o que na prática, muitas vezes, acaba funcionando como modo de instrumentalização das experiências populares. A tradição do recurso ao "mutirão" nas práticas de organização e de produção dos grupos populares, muito comum na nossa realidade, pode ser considerada como ilustrativa dessa articulação entre necessidades e saberes. O mutirão é um sistema de auto-organização popular e comunitário para a realização e a concretização de projetos, pois consiste em associar o conjunto dos membros de uma comunidade na execução dos seus próprios projetos coletivos.

Tais características de uma economia popular, onde a dimensão econômica aparece enraizada nas próprias relações sociais mais gerais - o que é comum nas formas comunitárias de organização popular -, são freqüentemente encontradas na base dos projetos de economia solidária, daí as expressões "economia popular e solidária" ou "socioeconomia da solidariedade", geralmente, utilizadas para descrever esse fenômeno da nossa realidade. No entanto, importa sublinhar que o projeto de uma economia solidária que ora se desenha pretende ir além das características próprias da economia popular. Sabemos que, em sua grande maioria, as experiências de economia popular - orientadas como são pela necessidade de gerar renda suficiente para a satisfação do consumo básico e assegurar a sobrevivência - garantem apenas a reprodução imediata das condições materiais de vida das pessoas, não conseguindo evitar a subordinação à lógica do capital. Funcionam, portanto, no plano de uma "reprodução simples" da vida, representando somente uma pequena extensão da unidade familiar.

Portanto, a capacidade dessa economia popular agir no espaço público, ou seja, de chamar atenção para problemáticas sociais mais gerais através da sua ação, parece muito pequena, restrita quase que inteiramente a uma dimensão comunitária. Esta, parece ser exatamente a vocação de algumas novas iniciativas que começam a surgir, e que consideramos como desenhando o projeto de uma economia popular e solidária. Tais iniciativas não se limitam à esfera da chamada "reprodução simples", e se orientam mais para a "reprodução ampliada" das condições de vida em sociedade. Isso quer dizer que sua ação abrange tanto o plano do nível de renda quanto aquele das suas condições de vida mais gerais, o que significa inscrever essa iniciativa igualmente no âmbito de uma reivindicação por direitos, implicando uma abertura da sua ação para um espaço público. ${ }^{11}$

\footnotetext{
${ }^{10}$ Parece oportuno distinguir economia popular de economia informal. A economia popular é definida pela referência ao tecido social local e suas práticas de reciprocidade como meio de elaboração das atividades econômicas. A economia informal, na maioria dos casos, refere-se a microprojetos individuais, que formam uma espécie de simulacro precário das práticas mercantis oficiais, e, desse modo, não apresentam uma articulação com base social local precisa ou com um saber ancestral. Na maioria das vezes, tal distinção aparece de modo bastante sutil à primeira impressão: economia informal e economia popular sendo comumente percebidas como expressões sinônimas. Isso decorre do caráter de movimento multiforme, próprio da idéia de economia popular. Esta compreende um amplo leque de iniciativas socioeconômicas, mais ou menos autocentradas ou heterocentradas (voltada para fora dela própria como organização), ou seja, oscilando da simples forma de sobrevivência dos mais pobres (marcados por um alto grau de precariedade institucional) até a idéia de modos de organização democráticos, abertos ao espaço público. Do mesmo modo, consideramos pertinente a distinção entre economia popular e economia subterrânea ou oculta. Esta última funciona, na maioria dos casos, baseada na violência, pois, geralmente, são formas despóticas de organização, calcadas em modos específicos de solidariedade. Esse esforço de distinção conceitual é particularmente importante, pois alguns poderiam identificar na organização do tráfico de drogas em certas favelas cariocas, por exemplo, sinais de manifestação de uma economia popular.
}

\footnotetext{
${ }^{11}$ Exemplo: a atuação de um cursinho pré-vestibular para estudantes carentes negros (caso da associação Steve Biko, em Salvador) beneficia não apenas, internamente, aqueles membros que conseguem auferir renda da sua atividade de ensino (embora sua relação com a instituição ultrapasse os motivos de um interesse utilitário), mas sobretudo um público maior que está na própria sociedade. Nesse caso, a ação organizacional pretende atacar uma problemática pública bastante clara, que poderíamos resumir em termos do acesso de certas parcelas da população à educação de nível superior.
} 
Nesses casos, as experiências de economia solidária através de sua ação econômica localizada tende à mobilizar atores institucionais diversos em torno da busca de soluções para problemas públicos concretos. Logo, essas iniciativas demonstram vocação para articular na sua ação organizacional uma dupla dimensão: aquela que poderíamos chamar de luta pela renda - mais próxima de uma tradição de movimento sindical - com outra que poderíamos denominar de luta por direitos sociais, típica da tradição dos chamados movimentos sociais.

Essas características específicas que conformam a extensão do fenômeno em diferentes realidades - baseadas numa reconfiguração das relações entre o econômico, o social e o político - atribuem ao tema da economia solidária uma complexidade que tende a escapar da leitura convencional em economia; leitura essa que a reduz à lógica mercantil utilitária. Assim, é imprescindível para o entendimento da singularidade desse fenômeno, uma redefinição da própria idéia de economia.

\section{Economia solidária e economia plural}

Por serem inúmeras as lógicas que atravessam a dinâmica da economia solidária nos diferentes contextos societários - haja vista a imbricação entre o social, o econômico e o político -, é a própria perspectiva de compreensão do funcionamento da economia real que deve ser colocada em termos mais complexos. Reduzir o fenômeno econômico ao princípio mercantil, como o faz a teoria econômica convencional, nesse caso, parece extremamente simplificador. Devemos raciocinar em termos de economia plural. Ou seja, em termos de uma economia que admita uma pluralidade de princípios do comportamento econômico. Esse conceito de economia plural nos permite dar conta de uma ampla dimensão da vida econômica, em especial aquela regida prioritariamente pela solidariedade, esquecida pela teoria econômica convencional (ou neoclássica). Essa dimensão não deve ser desprezada, pois dela depende a sobrevivência de grande parte da população no mundo. ${ }^{12}$ Compreendendo dessa forma, estaremos filiados à formulação polanyiana. Em sua obra A grande transformação, Polanyi já havia identificado quatro grandes princípios do comportamento econômico: o mercado auto-regulado, a redistribuição, a administração doméstica e a reciprocidade. Na modernidade, esses princípios podem ser resumidos a três formas de economia (LAVILLE, 1994; FRANÇA FILHO e LAVILLE, 2004), com a adoção de um sistema de direito jurídico-político que passa a regular as relações de trabalho, consideradas meio fundamental de produção e distribuição de riquezas. Assim, de modo esquemático, temos:

- uma economia mercantil - fundada no princípio do mercado auto-regulado. Trata-se de um tipo de troca marcado pela impessoalidade e pela equivalência monetária, limitando a relação a um registro puramente utilitário, pois nesse tipo de troca/relação, o valor do bem (medido pelo seu preço) fundamenta a lógica do sistema, ao contrário do primado do valor do laço, do liame (ou da relação social) que se busca numa lógica de reciprocidade;

- uma economia não-mercantil - fundada na redistribuição. Isto é, marcada pela verticalização da relação de troca e pelo seu caráter obrigatório, pois aparece a figura de uma instância superior (o Estado) que se apropria dos recursos, a fim de distribuí-los;

- uma economia não-monetária - fundada na reciprocidade. Isto é, um tipo de sistema de relação de trocas orientado segundo a lógica da dádiva, tal como formulada/descrita por Mauss. A dádiva compreende três momentos: aquele do dar, do receber e o do retribuir. Nesse tipo de sistema, os bens circulam de modo horizontal e o objetivo mesmo da circulação desses bens é a perenização dos laços sociais. A lógica da dádiva obedece a um tipo de determinação social específica; pois ao mesmo tempo livre e obrigada, a doação (ou esse registro de lógica) é essencialmente paradoxal. ${ }^{13}$

\footnotetext{
${ }^{12}$ Exemplo: na França, aproximadamente metade do produto nacional bruto, ou mesmo três quartos deste, não é apreendido, pois corresponde a formas de produção que não têm tradução monetária (INSEL, 1993). Se mesmo em países dito desenvolvidos os números impressionam, o que dizer do chamado Terceiro Mundo? Entretanto, faltam pesquisas a esse respeito. Merece registro, contudo, o fato de grande parte dessa " economia doméstica" ou "economia dos cuidados" ser largamente praticada pelas mulheres.

${ }^{13}$ Neste ponto, encontramos uma das descobertas empíricas centrais de Mauss em seu famoso Ensaio sobre o Dom (Essai sur le don. Forme et raison de l'échange dans les sociétés archaïques). Ou seja, aquela de que boa parte das sociedades humanas funcionou (como funciona em alguns casos ainda hoje)
} 
De forma esquemática, essa apresentação tem muito mais um objetivo pedagógico, no sentido de explicitar os diferentes registros de comportamento econômico em jogo na atividade econômica. Na prática, não somente as economias de mercado não são apenas mercantis, como também, sua própria prosperidade se apoia nos pólos não-mercantil - especialmente sobre toda a infra-estrutura financiada pelos poderes públicos - e não-monetário (também chamado pólo reciprocitário), isto é, sobre as relações familiares, de vizinhança, associativas etc., que contribuem de modo central para o processo de socialização dos indivíduos.

Tal tipo de argumentação permite ir além da idéia de economia de mercado como única fonte de riqueza, como possibilita condenar a redução das demais dimensões econômicas à condição de formas parasitárias desta. Essa visão mais ampla da economia implica ver esses três pólos na sua complementaridade, como criadores e, simultaneamente, consumidores de riqueza. Desse modo, são questionados a idéia de economia como algo reduzido exclusivamente a mercado, bem como o mito do progresso e a crença no crescimento econômico como fonte exclusiva de desenvolvimento e felicidade.

Trata-se, portanto, através da referência à noção de economia plural, de se pensar outra forma de produção e distribuição de riqueza. Significa pensar uma economia não necessariamente contra o mercado (imaginando ingenuamente ou autoritariamente que ele possa ser aniquilado), mas uma economia com mercado, sob a condição de que este seja submetido a outros princípios, que assimile outras práticas.

Partindo de uma definição de economia solidária como um conjunto de atividades que contribuem para democratizar a economia, a partir de engajamentos de cidadania, o desafio que se coloca a esse fenômeno, não é o de substituir a ação estatal -numa perspectiva filantrópica, por exemplo - sintomática de um processo de desregulamentação da economia. Ao contrário, seu objetivo é muito mais promover uma articulação junto à esfera pública, a fim de produzir uma "reimbricação" da economia num projeto político de integração social e cultural. É nesse sentido que consideramos que a economia solidária se apresenta como emanação de ações coletivas, sinalizando uma forma inédita de gestão pública.

Tal proposta será esclarecida se salientarmos dois importantes traços característicos, associados ao tema. Estes resumem a especificidade do fenômeno da economia solidária, segundo a perspectiva da sociologia e da antropologia econômica, levando a uma hipótese fecunda para sua interpretação como modo de regulação que aponta para uma nova forma de gestão pública. Esses traços são o que chamamos aqui de "hibridação de economias" e de "construção conjunta da oferta e da demanda".

O primeiro diz respeito à combinação de diferentes princípios econômicos, que são também lógicas de ação, e que estão presentes na maioria dos casos. Tal combinação se deve à natureza distinta das diversas fontes de recursos mobilizados na prática dessas iniciativas. Esses recursos podem ser de natureza mercantil, através de venda ou prestação de serviços a particulares (pessoa física ou jurídica), o que configura um recurso ao mercado. Também podem ser de natureza não-mercantil, através de subvenções ou de outros financiamentos à atividade, recebidos do poder público e/ou outras instituições públicas - caracterizando recurso ao Estado ou a instituições públicas da sociedade civil. Os recursos podem ser ainda de natureza não-monetária, através da participação voluntária de alguns membros, ou seja, doação sob a forma material ou humana (doação de tempo etc.), recurso privilegiado de uma lógica da reciprocidade ou uma lógica da dádiva. Essa hibridação de economias é o que permite, em muitos casos, a sustentabilidade e a perenidade dos projetos criados.

O segundo traço característico indica que, em matéria de economia solidária, oferta e demanda não podem se harmonizar por obra e graça da ação de uma mão invisível. A construção conjunta da oferta e da demanda indica que os serviços são concebidos e propostos em função de necessidades sociais reais, manifestadas

com base num registro de trocas muito diferente daquele da racionalidade econômica moderna. Com base nesse trabalho de Mauss, de 1923, e particularmente no seu conceito de dádiva, uma fecunda via paradigmática tem se desenvolvido no campo das ciências sociais, numa perspectiva de refundação de certos pressupostos dominantes nesse campo. Essa via concentra uma importante crítica sobre o legado economicista que tomou conta dessa área do conhecimento. São os trabalhos do chamado movimento antiutilitarista nas ciências sociais, amplamente publicados e debatidos pela Revue du MAUSS, na França, coordenada por Alain Caillé. Para uma leitura brasileira sobre o assunto, uma síntese importante desse paradigma é apresentado em França Filho \& Dzimira (1999). Ver ainda Caillé (1998 e 2002), Godbout (1998 e 2000) e Martins (2002). 
localmente. Essa construção conjunta da oferta e da demanda se torna possível em razão da interação entre os diferentes participantes da iniciativa e os seus estatutos particulares, que podem ser múltiplos ou difusos, isto é, simultaneamente usuários e assalariados ou usuários e voluntários. ${ }^{14}$ Daí a idéia de se pensar em termos de espaço público de proximidade como modo de concepção desses serviços, pois são debatidos problemas reais enfrentados no cotidiano, favorecendo o exercício de uma dimensão política nessas experiências.

\section{Considerações finais: economia solidária como um modo de gestão pública}

Muito embora existam importantes diferenças institucionais na manifestação do fenômeno da economia solidária, conforme os distintos contextos (FRANÇA FILHO, 2003b), a perspectiva socioantropológica ora adotada permite visualizarmos um conjunto de aspectos que estariam ausentes da análise, caso a opção fosse por um olhar exclusivamente econômico.

As duas características principais que atribuímos ao fenômeno se definem muito mais como uma vocação dessas iniciativas na sua prática concreta. $\mathrm{O}$ caráter híbrido dos recursos mobilizados nas experiências de economia solidária - entre atividades mercantis, não-mercantis e não-monetárias - indica a complexidade de uma gestão confrontada com uma pluralidade de lógicas de ação organizacional. Tal complexidade parece inerente a um fenômeno em que as diferentes dimensões da prática - social, política, econômica e cultural estão imbricadas. Nessa imbricação particular, tende a se inverter a articulação própria do mecanismo da empresa privada convencional, em que as demais dimensões (da prática) estão subordinadas à lógica econômica mercantil. Ou seja, na economia solidária é o econômico (redefinido), ou melhor, são as atividades de natureza econômica que estão a serviço dos objetivos sociais ou políticos da organização. Isso porque a lógica da acumulação privada não faz sentido nos empreendimentos que se definem antes de tudo como coletivos concretos, e que buscam acima de tudo a realização de finalidades públicas. Aqui, o caráter público da ação organizacional diz respeito ao fato dos empreendimento buscarem, em última instância, a solução de problemas reais que afetam a vida das pessoas na organização ou em torno dela. Esses problemas podem envolver questões ambientais ou a própria condição de vida social, relacionando-se a questões como moradia, educação, acesso a renda etc.

Essa é precisamente a razão pela qual consideramos que os projetos de uma economia popular e solidária têm vocação para a transformação institucional, mesmo que limitados a um plano local ou "microlocal", como no caso do contexto de um bairro, por exemplo. Afirma-se, nesse sentido, uma dimensão fundamentalmente política das práticas dessas formas de organização, um aspecto político que, nesse caso, não está relacionado a uma forma qualquer de tomada de poder institucional, mas a uma questão de agir no espaço público. Essa é a razão pela qual pensamos tais práticas como contribuindo para a construção de espaços públicos de proximidade. $\mathrm{E}$ isso, precisamente, em função da segunda característica que atribuímos ao fenômeno, aqui chamada de "construção conjunta da oferta e da demanda". Ou seja, nas práticas de economia solidária, a oferta, ou a elaboração de atividades econômicas, deve estar estreitamente vínculada às necessidades ou demandas reais expressas localmente (que não foram, obviamente, satisfeitas pelo mercado ou pelo Estado). Isso torna sem sentido o princípio da concorrência e aponta para uma das vocações principais de tais iniciativas, que é a de fomentar a construção de cadeias socioprodutivas locais, onde oferta e demanda são ajustadas pela ação consciente e deliberadamente acordada entre produtores (ou prestadores de serviços) e consumidores locais.

O compromisso próprio das experiências de economia solidária, e que consideramos profundamente político, é exatamente aquele da mudança nas condições de vida, tanto das pessoas envolvidas diretamente nos empreendimentos, quanto da própria realidade local na qual a iniciativa se insere. Evidentemente, trata-se de

\footnotetext{
${ }^{14}$ É o caso de uma dinâmica associativa em que a atividade da organização beneficia os próprios moradores de um bairro, os quais também participam como membros da associação. Dois exemplos são as já mencionadas régies de quartier, na França (FRANÇA FILHO, 2002c) e Associação de Moradores do Conjunto Palmeiras (Asmoconp), no Ceará, (FRANÇA FILHO e SILVA Jr., 2003). Neste ultimo caso, a associação estimula de modo bastante enfático, em alguns dos seus projetos, que se acabe com a separação entre produtor e usuário, ao exercitar um conceito que se tornou um dos eixos do discurso da associação: "prossumidor".
} 
uma espécie de política da vida cotidiana, quando indivíduos decidem exercer cidadania, participando de coletivos concretos que atacam problemas públicos através da elaboração de atividades econômicas.

Desse modo, ao serem confrontados problemas públicos concretos, expressos num nível local, as experiências de economia solidária acabam por inventar formas inéditas de ação pública, uma vez que são oriundas da própria sociedade. Tais iniciativas acabam por indicar os limites da ação do Estado a nível local, questionando o seu papel e revelando as possibilidades da sociedade civil de praticar a gestão pública.

Evidentemente que essa discussão deve ter continuidade, sobretudo, visando a um exame mais exaustivo das implicações, em termos de limites e desafios desse modo renovado de gestão pública. Nesse sentido, os estudos de caso constituem um recurso da pesquisa científica extremamente útil. Por ora, salientemos uma modesta contribuição que o debate aqui proposto nos deixa. Ou seja, a desconstrução de dois grandes pressupostos que têm norteado a relação entre as esferas econômica e política na sociedade contemporânea. O primeiro é o de não resumir o econômico ao mercantil, redefinindo-se o sentido das práticas econômicas a partir da noção de economia plural. O segundo é o de não resumir o político ao governamental, revelando as possibilidades contidas na própria sociedade, na sua capacidade de formular novos modos de gestão pública. 


\section{Referências bibliográficas}

BORZAGA, C.; MITTONE, L. The multistakeholders versus the non- profit organization. University of Trento, 1997. (Draft paper, n.7).

CAILLÉ, A. Critique de la raison utilitaire. Paris: La decouverte, 1989. (Coll. Agalma).

CLEM ENT, H.; GARDIN, L. L'entreprise social. Domont, France: Thierry Quinquenton Éditeur, 1999. (Coll. Les notes de I'Institut Karl Polanyi).

DONZELOT, J.; ESTEBE, P. L'Etat animateur - essai sur la politique de la ville. Paris: Esprit, 1994.

; ROMAN, E. (Org.). Face à l'exclusion: le modèle français. Paris: Esprit, 1991.

EME, B.; LAVILLE, J.- L. (Org.). Cohésion social et emploi. Paris: Desclée de Brouwer, 1994. (Coll. Sociologie Économique).

$\overline{1} \overline{9} \overline{9} \overline{6}$. (Org.). Economie plurielle, économie solidaire : précisions et compléments. La Revue du MAUSS Semestrielle, Paris, n.7,

EVERS, A. Les dimensions sociopolitiques du tiers secteur - les contributions théoriques européennes sur la protection sociale et l'économie plurielles. Revue Sociologie du Travail, v.42, n.4, oct./déc. 2000.

FRANÇA FILHO, G. C. A problemática da economia solidária: uma perspectiva internacional. Revista Sociedade \& Estado, Brasília, Departamento de Sociologia - UnB, v.14, n.1-2, p.243-75, jan./dez. 2001.

Sociétés en mutation et nouvelles formes de solidarité: le phénomène de l'économie solidarie en question - l'expérience des Régies de Quartier au carrefour de logiques. Villeneuve d'Asque: Presses Universitaires du Septentrion, 2002a. (Coll. Thèse à la Carte).

. Terceiro setor, economia social, economia solidária e economia popular: traçando fronteiras conceituais. Bahia Análise e Dados, Salvador, SEl/Governo da Bahia, v.12, n.1, p.9-19, jun. 2002b.

. Associativismo, exclusão social e novas formas de organização - um exemplo de economia solidária na França: o caso das Régies de Quartier. In: FISCHER, T. (Org.). Gestão do desenvolvimento e poderes locais: marcos teóricos e avaliação. Salvador: Casa da Qualidade, 2002c. p.298-314.

. A perspectiva da economia solidária. In: FISCHER, T. (Org.). Gestão do desenvolvimento e poderes locais: marcos teóricos e avaliação. Salvador: Casa da Qualidade, 2002d. p.123-36.

. A temática da economia solidária e suas implicações originais para o campo dos estudos organizaci onais. Revista de Administração Pública - RAP, FGV-RJ, v.37, n.01, jan./fev. $2003 a$. n. $21,2003 \mathrm{~b}$

L'économie solidaire en France et au Brésil: regards croisés. La Revue du MAUSS Semestrielle, Paris, Ed. La Découverte/MAUSS,

FRANÇA FILHO, G. C.; DZIMIRA, S. Economia solidária e dádiva. Organizações e Sociedade, Salvador, v.6, n.14, 1999.

; -__-_._. Don et économie solidaire. Paris: MAUSS, 2000.

; LAVILLE, J.- L. Economia solidária: uma abordagem internacional. Porto Alegre: EDUFRGS/EDUFBA, 2004.

; SILVA J r., J. T. Fato associativo e economia solidária: a experiência do Banco Palmas no Ceará. Colóquio Internacional sobre Poder local, 9., Salvador. Anais... Salvador, 2003.

GUERIN, H.; VALLAT, D. Les finances solidaires. Domont, Paris: Thierry Quinquenton éditeur, 1999. (Coll. Les notes de l'Institut Karl Polanyi).

HEBER-SUFFRIN, C. Le savoir, la reciprocité et le citoyen. Paris: Desclée de Brouwer, 1998.

INSEL, A. La part du don, esquisse d'évaluation. La Revue du MAUSS Semestrielle, Paris, n.1, 1993.

KRAYCHETE, G., LARA, F.; COSTA, B. (Org.). Economia dos setores populares: entre a realidade e a utopia. Petrópolis, Vozes , 2000.

LAVILLE, J.- L. Les services de proximité en Europe. Paris: Syros, 1992.

. Economie et solidarité: esquisse d'une problématique. In: Laville (Org.). L'économie solidaire - une perspective internationale. Paris: Desclée de Brouwer, 1994. (Coll. Sociologie Économique).

. La crise de la condition salariale : emploi, activité et nouvelle question sociale. Le travail, quel avenir? Paris: Gallimard, 1997. (Coll. Folio/Actuel).

Une troisième voie pour le travail. Paris: Desclée de Brouwer, 1999. (Coll. Sociologie Économique).

; NYSSENS, M. L'entreprise sociale, éléments pour un approche théorique. Paris: Crida, 1999. (documento de trabalho).

MAUSS, M. Essai sur le don. Forme et raison de l'échange dans les sociétés archaïques. Paris: Quadrige, PUF, 1950. (Coll. Sociologie et Anthropologie). 
NYSSENS, M. Les approches économiques du tiers secteur - apports et limites des analyses anglo-saxonnes d'inspiration néo- classique. Revue Sociologie du Travail, n.4, v.42, oct./déc. 2000.

PESTOFF, V. A. Beyond the market and State, social enterprises and civil democracy in a welfare society. Aldershot-Bookfield/USASingapore-Sydney: Ashgate, 1998.

POLANYI, K. La grande transformation. Aux origines politiques et économiques de notre temps. Paris: Gallimard, 1983.

ROSANVALLON, P. La nouvelle question sociale - repenser l'Etat-providence. Paris: Seuil, 1995.

SERVET, J. M. (Org.). Une économie sans argent - les systèmes d'echange local. Paris: Seuil, 1999.

; VALLAT, D. (Org.). Exclusion et liens financiers - rapport du Centre Walras 1999-2000. Paris: Econômica, 1999. 